2011-5

\title{
Aerodynamic Performance of Extended Formation Flight
}

\author{
Andrew Ning \\ Brigham Young University - Provo, aning@byu.edu \\ Tristan Flanzer \\ Stanford University \\ Ilan Kroo \\ Stanford University
}

Follow this and additional works at: https://scholarsarchive.byu.edu/facpub

Part of the Mechanical Engineering Commons

\section{Original Publication Citation}

Ning, A., Flanzer, T., and Kroo, I., "Aerodynamic Performance of Extended Formation Flight," Journal of Aircraft, Vol. 48, No. 3, May 2011, pp. 855-865. doi:10.2514/1.C031046

\section{BYU ScholarsArchive Citation}

Ning, Andrew; Flanzer, Tristan; and Kroo, llan, "Aerodynamic Performance of Extended Formation Flight" (2011). Faculty Publications. 1676.

https://scholarsarchive.byu.edu/facpub/1676

This Peer-Reviewed Article is brought to you for free and open access by BYU ScholarsArchive. It has been accepted for inclusion in Faculty Publications by an authorized administrator of BYU ScholarsArchive. For more information, please contact ellen_amatangelo@byu.edu. 


\title{
Aerodynamic Performance of Extended Formation Flight
}

\author{
S. Andrew Ning*, Tristan C. Flanzer*, and Ilan M. Kroo ${ }^{\dagger}$ \\ Stanford University, Stanford, CA, 94305
}

\begin{abstract}
The aerodynamic benefits of formation flight have been known for nearly a century. However, these benefits have yet to be realized in a commercial environment in part due to the hazards associated with close formation flight. This paper explores a more practical approach to formation flight called extended formation flight, which takes advantage of the persistence of cruise wakes and extends the streamwise spacing between the aircraft by at least ten spans. Induced drag savings are estimated in an incompressible analysis considering the effects of wake rollup, vortex decay, vortex instabilities, vortex motion, atmospheric turbulence and stratification, and stochastic behavior. Extended formations are found to be unpractical for streamwise spacings larger than about 50 spans between each aircraft. For spacings around 10 to 40 spans, with low to moderately-low atmospheric turbulence, a two aircraft formation has a maximum induced drag reduction of $30 \pm 3 \%$, while a three aircraft formation has a maximum induced drag reduction of $40 \pm 6 \%$. At these distances, aircraft tracking error is the most significant contribution to the variation in drag savings. Studies of transonic effects, ride quality concerns, and control and sensing strategies are necessary to further evaluate the potential of extended formation flight.
\end{abstract}

\section{Nomenclature}

$\begin{array}{ll}A & \text { area } \\ a & \text { core radius } \\ A R & \text { aspect ratio } \\ A R_{0} & \text { aspect ratio based on vortex spacing } b_{0} \\ b & \text { wingspan } \\ b_{0} & \text { initial spacing between the vortices } \\ C_{L} & \text { lift coefficient } \\ g & \text { acceleration of gravity } \\ k & \text { perturbation wavenumber } \\ N & \text { Brunt-Väisälä frequency } \\ q & \text { rms turbulent velocity } \\ r & \text { radius } \\ t & \text { time } \\ w & \text { vertical component of velocity } \\ w_{0} & \text { initial descent rate of vortex pair }\left(\frac{\Gamma_{0}}{2 \pi b_{0}}\right) \\ x & \text { streamwise position } \\ y & \text { lateral position } \\ z & \text { vertical position } \\ \text { Symbols } & \\ \delta & \text { lateral spacing between inner vortices } \\ \epsilon & \text { eddy dissipation rate } \\ \Gamma & \text { circulation strength }\end{array}$

* Doctoral Candidate, Department of Aeronautics and Astronautics, AIAA Student Member.

${ }^{\dagger}$ Professor, Department of Aeronautics and Astronautics, AIAA Fellow. 


$\begin{array}{ll}\gamma & \text { vorticity } \\ \Gamma_{0} & \text { initial circulation of vortex pair } \\ \Lambda & \text { longitudinal turbulent length scale } \\ \nu & \text { effective kinematic viscosity } \\ \phi & \text { disturbance vector } \\ \sigma & \text { standard deviation } \\ \theta & \text { potential temperature } \\ \text { Superscripts } \\ * & \text { normalized quantity } \\ * & \text { perturbation quantity }\end{array}$

\section{Introduction}

Aerodynamicists and biologists have long recognized the benefit of formation flight. Wieselsberger was the first to attempt to quantify the aerodynamic advantages of formation flying. ${ }^{1}$ Using newly developed ideas from Prandtl's lifting line theory, he represented three birds in a diagonal formation using horseshoe vortices and showed a corresponding reduction in induced drag due to the influence of the bound and trailing vortices. Conceptually, formation flight can be understood by looking at the counter-rotating vortices generated by a finite wing. A second bird, properly positioned outboard of one of these vortices, benefits from the rising air of the upstream vortex and experiences a reduction in the power required to fly. Lissaman and Shollenberger published theoretical results that predicted a flock of 25 birds has a $71 \%$ greater range than a single bird. ${ }^{2}$ For the last few decades, Hummel has published a number of papers that confirmed and expanded upon earlier findings by using both classical aerodynamic theory and experiment. ${ }^{3,4}$ More recently, biologists have confirmed that pelicans exhibit reduced heartrate while in formation, providing further evidence of its benefits. $^{5}$

The application of formation flight to aircraft has received considerable attention as well. This is especially true in the last ten years as advancements in technology have enabled the use of precision navigation and control to maintain formations. The aerodynamics have been studied using both analytic and experimental techniques. Analytic treatments have ranged from representing aircraft with single horseshoe vortices, ${ }^{6,7}$ to using vortex lattice codes. ${ }^{7-9}$ Experiments have included wind tunnel testing as well as flight tests. Flight tests confirm that significant reductions in drag are achievable. ${ }^{6,10}$ The most serious flight test program to date was funded by NASA as part its Revolutionary Concepts Program. ${ }^{11-13}$ Despite being canceled midway through due to budgetary constraints, the goal of at least a $10 \%$ drag reduction was surpassed, with data indicating that a 15-20\% reduction in drag had been achieved for the trailing aircraft. Recent system level analyses of formation flight have demonstrated that a $13 \%$ reduction in fuel burn is achievable under a realistic commercial scenario. ${ }^{14}$ Comparisons between experiment and low order codes have shown fairly good agreement in the basic trends and magnitude of induced drag savings for close formation flight.

Close formation flight, however, is of limited applicability to commercial aviation. Commercial aircraft flying within a few spans of each other at cruise speeds, present an unacceptably high risk of collision. Our concept of extended formations helps to ameliorate the dangers of close proximity flying. Extended formations are separated in the streamwise direction by more than ten spans. This allows the formations to fly at safer separation distances, yet still retain most of the benefit of formation flying. While close formation flight has received much attention in the literature, this concept of extended formation flight has not.

Munk's stagger theorem ${ }^{15}$ suggests that the total induced drag of the formation should not change as the streamwise separation is increased, but the large separation distances of extended formation flight violate some of the theorem's assumptions. At large distances, considerations such as circulation decay and vortex instability become important effects to be considered. This paper attempts to quantify the aerodynamic benefits of flying in formation at these large separation distances.

This paper is not meant to be as a comprehensive analysis of the benefits of extended formation flight, or an evaluation of its practicality in a commercial aviation environment. There are other considerations such as transonic effects, handling and ride quality issues due to flying through a dynamic wake and through "dirty" fluid, control and sensing requirements and limitations, and other logistical questions that still need to be evaluated. Further, the analysis does not attempt to estimate fuel burn savings or even total drag savings, only the induced drag savings of each formation is evaluated. A more complete drag assessment would require higher fidelity analyses for particular configurations, especially for those that fly at transonic 
speeds. The intent of this paper is to propose a safer alternative to close formation flight and evaluate its primary aerodynamic benefits. This study estimates the induced drag savings of formations of aircraft in the presence of uncertainty in model parameters, variation in atmospheric properties, and limitations of positioning accuracy. Further, it examines the extent of streamwise separation that may be practically utilized for extended formations. It should be emphasized that all induced drag savings are reported for the formation as a whole, and not for any individual aircraft.

The paper is divided into three sections. The first section discusses the methods used to quantify the aerodynamic benefits of extended formation flight in a realistic environment. The second section discuss results for a two aircraft formation, and several different three aircraft formations. The final section assesses which factors contribute most to the variation in induced drag savings.

\section{Methods}

The development of wakes behind aircraft has been studied extensively by researchers for decades. Airport capacity is constrained by FAA spacing requirements, rules that have been set due to the danger of unexpected wake vortex encounters. Consequently, a great deal of effort in understanding wake behavior has occurred. This paper leverages that previous work, which is of interest in the case of extended formation flight.

In order to study some of the performance benefits and limitations of extended formation flight we include the effects of wake rollup, viscous decay, vortex instabilities, and vortex propagation due to induced velocities and turbulent gusts. The details of the various methods are described in the following sections. An incompressible analysis is used as it is assumed sufficient to show many of the trends. However, for practical application many of the compressible effects cannot be ignored. As an example, the amount of aileron deflection allowed to trim the aircraft while in formation will likely be limited by buffet requirements at cruise speeds. These transonic effects may require the aircraft to fly further from the optimal location for induced drag savings, the use of spanwise load tailoring, or a complete redesign of the wing.

\section{A. Wake Rollup}

As a consequence of a non-uniform spanwise lift distribution, the vortex sheet shed from the trailing edge of a finite wing rolls up from its initially flat configuration. In close formation flight, a flat wake model is appropriate for many applications because the true wake deviates only slightly from the idealized flat wake. However, in extended formation flight, this model is likely to be inadequate because of the larger streamwise separation between aircraft. Wake rollup is a complex process, but the separation distances in extended formation flight are large enough that we need not be concerned with the intermediate stages of the rollup process. Typically the wake behind an aircraft is considered completely rolled up within a few spans. ${ }^{16}$ Since we are interested in steady cruise conditions with separation distances more than a few spans, we can apply far-field wake models based on conservation principles. These models are simplified by the fact that the rollup process is typically rapid enough that viscous effects can be neglected during this phase, ${ }^{16}$ and that the wake velocities are very nearly two dimensional. ${ }^{17}$ The results from the rollup model can then be used as initial conditions for a viscous wake decay model. ${ }^{16}$

Several models for the rolled up inviscid wake have been proposed and used throughout the years. Many of the models begin with an assumption on how the vorticity is distributed, such as in the Rankine vortex or the Lamb-Oseen vortex. These models have the advantage of simplicity but require some other method to determine the appropriate core size. This is often done by a method first proposed by Prandtl ${ }^{18}$ and more fully developed separately by Milne-Thompson ${ }^{19}$ and Spreiter \& Sacks. ${ }^{20}$ This method is based on conservation of mechanical energy applied over a large control volume containing the aircraft. It is assumed that the induced drag of the aircraft is approximately equal to the kinetic energy of the fluid in the Trefftz plane. This approach neglects kinetic energy due to axial velocities, and energy lost to viscous dissipation. While the approach is a sensible one, the choice of vorticity distribution is rather arbitrary. The Rankine vortex is commonly used with the Prandtl method leading to a core size prediction a little over $8 \%$ of the wing span. ${ }^{20}$ However, agreement with experimental results is rather poor. Experimental data show smaller core sizes, and that the assumption of all the vorticity being contained within the core is rather inaccurate. ${ }^{16}$ Other simple vorticity profiles such as the Lamb-Oseen vortex can be used with the Prandtl method but core size is still over predicted. ${ }^{21}$

We use a wake rollup method first proposed by Betz, ${ }^{22}$ and later made more visible by Donaldson. ${ }^{23}$ The 
method has shown excellent agreement with experiment. ${ }^{21,24}$ The Betz model does not require an assumption on the assumed form of the vorticity distribution, but rather computes it based on other invariants. For an incompressible, 2-D, finite vorticity distribution, using the continuity equation and the vorticity equation, it can be shown that the time derivatives of the following quantities are all zero. ${ }^{25}$

$$
\begin{gathered}
\Gamma=\int \gamma d A \\
\Gamma_{y}=\int y \gamma d A \\
\Gamma_{z}=\int z \gamma d A \\
\Gamma_{r}=\int\left(y^{2}+z^{2}\right) \gamma d A
\end{gathered}
$$

The Betz model assumes that each vortex rolls up into axially symmetric vortices and that the influence of one vortex on the other during the rollup process is negligible. This allows each half of the flow field to be considered separately leading to the following equations:

$$
\begin{gathered}
\frac{d \Gamma}{d t}=0 \\
\frac{d \Gamma_{y}}{d t}=0 \\
\frac{d \Gamma_{z}}{d t}=-\left.\int_{-\infty}^{\infty} \frac{w^{2}}{2}\right|_{y=0} d z \\
\frac{d \Gamma_{r}}{d t}=-\left.\int_{-\infty}^{\infty}(z-\bar{z}) \frac{w^{2}}{2}\right|_{y=0} d z
\end{gathered}
$$

where $\bar{y}$ and $\bar{z}$ are the centroids of vorticity $\left(\bar{y}=\Gamma_{y} / \Gamma_{0}\right.$ and $\left.\bar{z}=\Gamma_{z} / \Gamma_{0}\right)$.

In the present form computation of the rollup procedure is still not straightforward. Betz made one final simplifying assumption. $\Gamma_{r}$ is a measure how much the vorticity is spread about its centroid. As seen from this last equation $\frac{d \Gamma_{r}}{d t}$ is zero if the vorticity distribution is vertically symmetric. This is the case both initially as a flat wake and finally when roll up is complete. Betz assumed that $\Gamma_{r}$ should not change significantly during the entire roll up process, and that it should also be approximately conserved locally. ${ }^{25}$ Donaldson, ${ }^{24}$ Rossow, ${ }^{26}$ and Jordan ${ }^{27}$ were independently able to discover a simpler relationship relating the initial spanwise distribution of vorticity, and the final rolled up distribution.

$$
\begin{gathered}
r=\bar{y}-y \\
\Gamma_{r}(r)=\Gamma(y)
\end{gathered}
$$

This relationship provides a mapping from the original lift distribution to an axially symmetric rolled up wake (see Donaldson ${ }^{25}$ for further details on the present discussion).

Rossow has shown that although the assumption of axially symmetric vorticity distributions may seem restrictive, this "first order" approximation is surprisingly accurate, even when superimposing multiple axially symmetric vortex pairs in a flowfield. ${ }^{28}$ He has also shown that starting with conservation of energy as one of the invariants, the end result is the same as that of Betz method. A limitation of the original Betz method is that it is applicable only to lift distributions which are close to elliptic (more specifically to lift distributions in which the absolute value of the vorticity decreases monotonically from tip to root). However, a number of extensions to this method have been proposed throughout the years to increase its range of applicability. For example, Mason has extended the method to any wing planform that can be represented using lifting line theory. ${ }^{29}$ Donaldson and Rossow have extended the methodology to complex lift distributions, such as those generated from a flaps-down configuration. ${ }^{24,26}$ These methods may be important in extended formation flight in order to study wings with winglets. These extended Betz methods have shown reasonable agreement with experiment, however it is not always clear in the case of multiple vortices whether these vortices will remain distinct, merge, or one will disperse and distribute its vorticity around another vortex. ${ }^{25}$ 


\section{B. Core Size}

As noted previously, the results from using a Rankine vortex grossly overestimate core size (radius of peak velocity) when compared to experimental results. Spalart notes that the viscous core is often surprisingly small, about $1 \%$ of the span, and that the growth of the core is very slow. ${ }^{21}$ A relatively recent series of experimental tests were conducted to estimate wake vortex core size. ${ }^{30}$ These tests were conducted at different airports (Wallops Island, Idaho Falls, JFK) with different aircraft (C-130, B-727, B-757, B-767, MD-11) and used different experimental methods (velocity probes measured from a follower aircraft, hot film anemometers on an instrumented 200 foot tower, ground based continuous wave LIDAR). Figure 1, whose data is taken from their paper shows that the results were fairly consistent among all the tests, and that core size was relatively independent of distance behind the aircraft. This data is also consistent with earlier flight tests which showed core sizes of about $2 \%$ span even at 200 spans behind the airplane. ${ }^{31}$

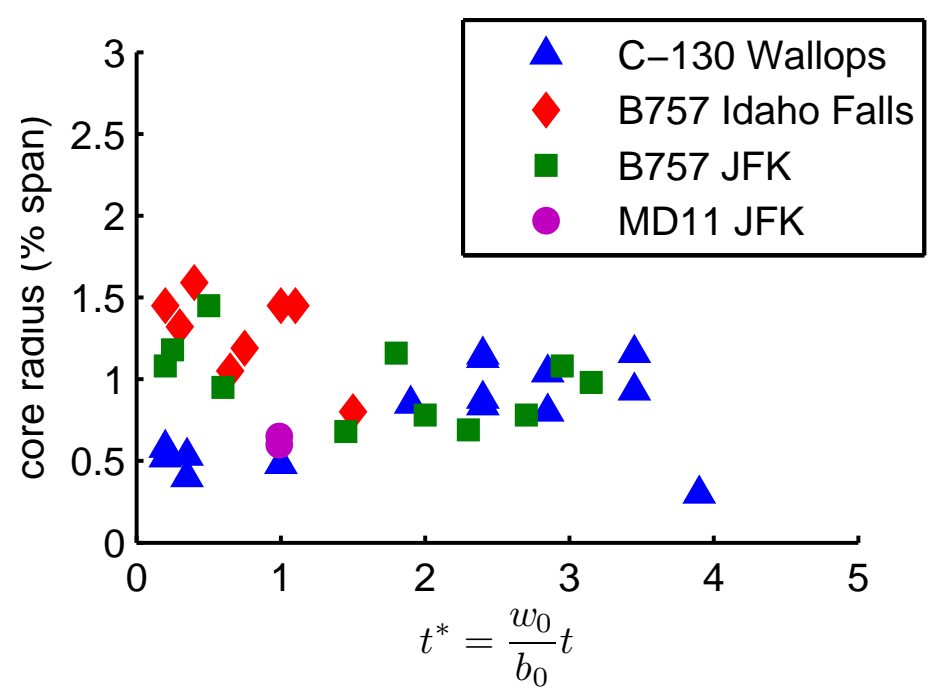

Figure 1: Vortex core radius as a function of normalized time. (Data for figure taken from Delisi et al..$^{30}$ )

The normalized time used in this paper is defined as

$$
t^{*}=\frac{w_{0}}{b_{0}} t
$$

For an elliptic lift distribution this definition of normalized time can be rearranged to give

$$
\frac{x}{b} \approx 6 \frac{A R}{C_{L}} t^{*}
$$

For an aspect ratio 8 wing with a lift coefficient of 0.5 , a normalized time of 1 corresponds roughly to 100 spans. Since the downstream spacing of our formations are well within the normalized times examined in the experiments, we use the result that core size should be roughly constant and be between about 1-2\% of the wing span.

These measurements of vortex core radius, similar to most experimental reports in the literature, are given relative to the wing span. However, this is not necessarily a relevant parameter to reference core size to. As an example, let us imagine the two different lift distributions shown in Figure 2. The first is an elliptic lift distribution, while the second is the same lift distribution with a flat section added inboard. The second lift distribution corresponds to an aircraft with a larger span, but the constant lift section does not add any additional vorticity. In effect we have just taken the same rolled-up vortex pairs from the first lift distribution and increased the spacing between them. If we use the criteria that core size is a fixed fraction of wing span then we would reach the unexpected conclusion that the second vortex pair must have larger core sizes. While the case may be a little contrived, in formation flight a trailing aircraft often has a flatter lift distribution due to increased upwash at its tips. If we have a third aircraft in the formation then it is important to correctly estimate the core size from the second aircraft with the flatter lift distribution. 

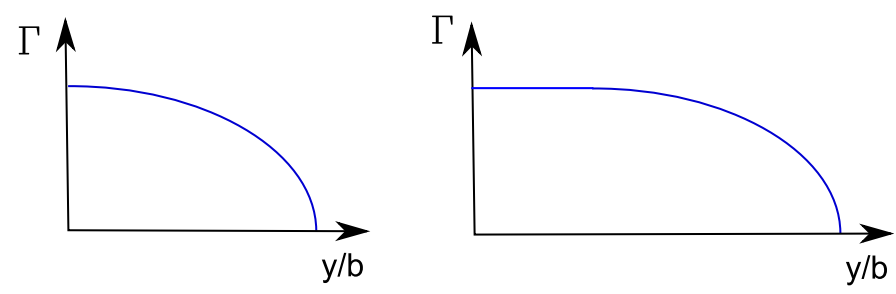

Figure 2: Two example lift distributions to demonstrate fallacy of referencing core size relative to wing span.

A more relevant parameter to reference core size to is what we will call the vortex radius. Since there is not a sharp boundary defining the vortex size, for this analysis we define it to be the radius at which $99 \%$ of the circulation is contained in (this radius is similar to the parameter denoted $r_{2}$ in Spalart's work ${ }^{21}$ ). An example is shown in Figure 3. For an elliptic lift distribution this radius is found to be $32.5 \%$ of the wing span (or $83 \%$ of the Betz radius). Thus, a core radius of $1-2 \%$ span for an elliptic lift distribution corresponds to a core radius which is $3-6 \%$ of the vortex radius. This method avoids the problems associated with using wing span as a reference parameter in specifying core size.

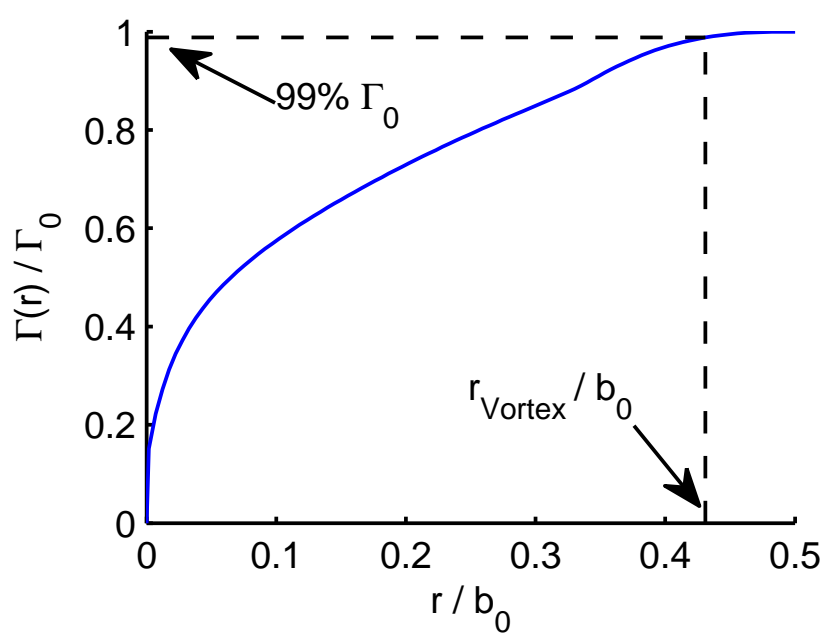

Figure 3: A representative vortex circulation distribution showing the definition of vortex radius used here.

In this analysis, the swirl velocity predicted from the solid body core is joined to the swirl velocity predicted by the Betz method with a cubic spline joining the two pieces. Smoothness in the swirl velocity is important since gradient based optimization is used for some of the results. A comparison with the wake rollup method used here, and a higher fidelity 2D Navier Stokes calculation done by Spalart ${ }^{32}$ is shown in Figure 4. Good agreement is observed between the two methods. The result in the figure is using a core size of $4.5 \%$ of the vortex radius (the mean value from our estimation method). Also shown in the figure is a comparison to a commonly used Rankine-Prandtl vortex.

As mentioned, a flat wake model is often used in close formation flight analyses. It is of interest to compare the induced drag savings predicted from a flat wake model to that from the Betz with core model. Figure 5 shows a comparison between these models for a two aircraft formation of identical aircraft, with ten spans streamwise separation. In the Betz case, the trailing aircraft is vertically aligned with the center of the wake. As the wake evolves behind the lead aircraft the optimal location for the trailing aircraft changes, as does the magnitude of the induced drag savings.

A corresponding contour plot for the Betz with core model is shown in Figure 6. The effect of rollup and descent of the wake is clearly seen. The area for which $20 \%$ or more induced drag savings is realized is encircled. This highlights the large region for which significant drag reductions are realized. The computation of induced drag is discussed in more detail in a later section. 


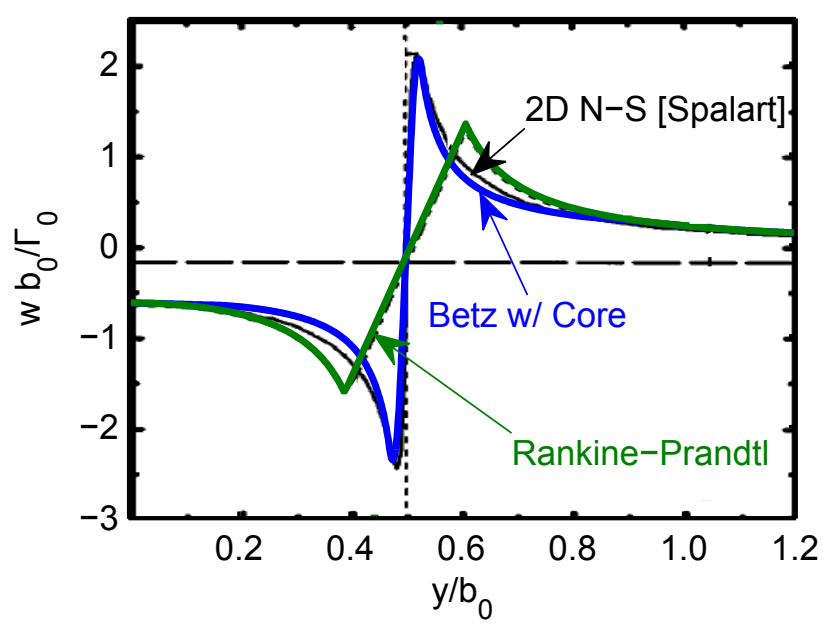

Figure 4: Good agreement is shown between our modified Betz model and a 2D Navier Stokes computation done by Spalart. ${ }^{32}$ Also shown is the Rankine-Prandtl model for comparison. (only the right half of the symmetric velocity profile is shown)

\section{Wake Decay}

One of the first widely recognized models for vortex decay was due to Greene. ${ }^{33}$ His model used three terms to predict wake motion and decay. The first term in his model is due to drag on an oval of fluid treated like a solid body. Later models discard this term because as noted by Sarpkaya, a drag force acting on a free vortex pair is not hydrodynamically sound. ${ }^{34}$

The second term is a buoyancy force due to stratification of the atmosphere. This force is a function of the Brunt-Väisälä (B-V) frequency, which characterizes the frequency of oscillation for a fluid particle displaced from equilibrium in a statically stable atmosphere. The B-V frequency is given by

$$
N=\sqrt{\frac{g}{\theta} \frac{d \theta}{d z}}
$$

and is normalized as

$$
N^{*}=\frac{N b_{0}}{w_{0}}
$$

The last term is a viscous term due to atmospheric turbulence. Although Greene used a root mean square turbulence velocity in his model, most later models use the eddy dissipation rate as it is a more fundamental turbulence parameter. ${ }^{34}$ Crow and Bate ${ }^{35}$ showed that the appropriate normalization for the eddy dissipation rate is

$$
\epsilon^{*}=\frac{\left(\epsilon b_{0}\right)^{1 / 3}}{w_{0}}
$$

Over the years many models have been proposed to extend and refine this model. In recent years there are mainly three models which have undergone continued development and testing. ${ }^{36}$ These models are due to Holzäpfel, ${ }^{37,38}$ Sarpkaya, ${ }^{34}$ and Transport Canada. ${ }^{39}$

For this analysis the Holzäpfel model is used because it tends to be more conservative for our application, and it allows uncertainty analysis to be more easily incorporated. The form of the circulation decay is based on an analytical solution to the Navier-Stokes equations for plane, rotating flow.

$$
\frac{\Gamma(r, t)}{\Gamma_{0}}=1-\exp \left(\frac{-r^{2}}{4 \nu t}\right)
$$

Both LES and experimental data suggest that vortex decay occurs in two phases, a diffusion phase and a rapid decay phase. ${ }^{36,40}$ The Navier-Stokes solution is modified to allow for these two phases, and to adjust 

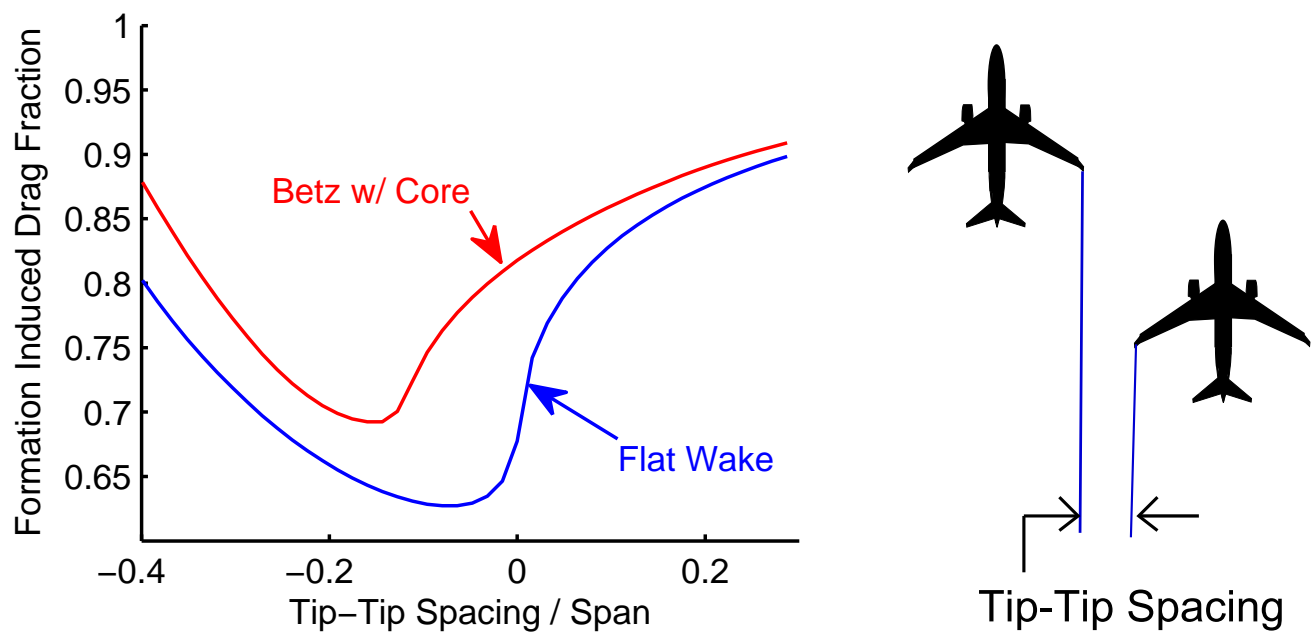

Tip-Tip Spacing

Figure 5: Comparison of induced drag savings between flat wake model and Betz with core vortex model for a two aircraft formation with ten spans streamwise separation.

the strength at initial rollup. For the diffusion phase normalized circulation decay is given by

$$
\Gamma^{*}=A-\exp \left(\frac{-R^{* 2}}{\nu_{1}^{*}\left(t^{*}-T_{1}^{*}\right)}\right)
$$

and during the rapid decay phase

$$
\Gamma^{*}=A-\exp \left(\frac{-R^{* 2}}{\nu_{1}^{*}\left(t^{*}-T_{1}^{*}\right)}\right)-\exp \left(\frac{-R^{* 2}}{\nu_{2}^{*}\left(t^{*}-T_{2}^{*}\right)}\right)
$$

where $A, R^{*}, T_{1}^{*}, T_{2}^{*}, \nu_{1}^{*}, \nu_{2}^{*}$ are coefficients tuned from LES simulations. The time when rapid decay begins $\left(T_{2}^{*}\right)$ is based on the work of Sarpkaya ${ }^{34}$ and that of Crow and Bate ${ }^{35}$ with slight modification to better agree with other published LES data. Holzäpfel's model has been demonstrated to produce reasonable agreement with flight test data. ${ }^{41}$

A few typical results from the Holzäpfel model are shown in Figure 7 for low, moderate, and high turbulence in a neutrally stratified atmosphere. From the figure we can see that there is a diffusion range which is self-similar, followed by a rapid decay range which is dependent on turbulence and stratification levels. The shaded regions show the $95 \%$ confidence intervals for wake strength as a function of normalized time. The incorporation of uncertainty analysis is discussed later in section G. 


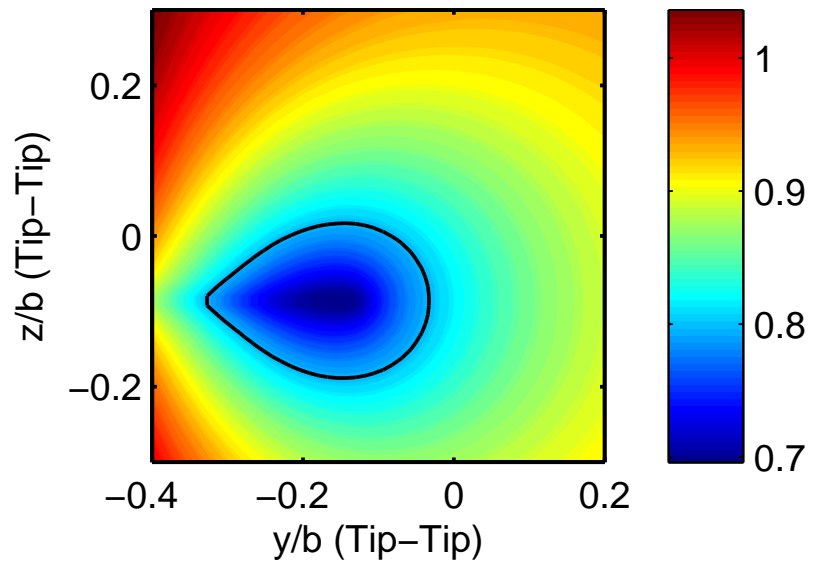

Figure 6: Contours of the formation induced drag fraction for a two aircraft formation with ten spans streamwise separation. Solid line contour indicates region of $20 \%$ or more induced drag savings for the formation.

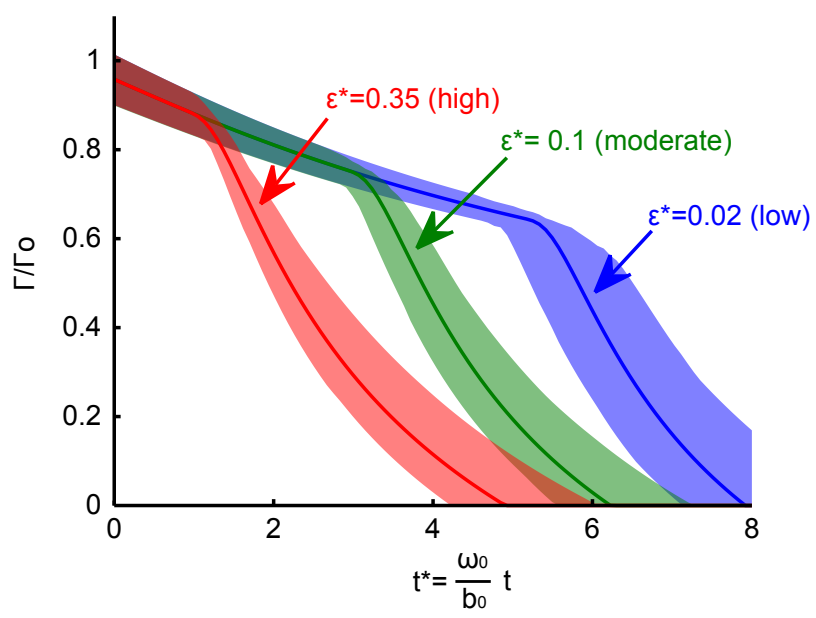

Figure 7: Normalized vortex circulation as a function of normalized time for three different turbulence levels. Shaded regions represent $95 \%$ confidence intervals. 


\section{Linearized Vortex Filament Method}

The wake decay models of the previous section are based on the wake behind a single aircraft. For extended formation flight, if the formation consists of more than two aircraft, we must also consider the interaction of vortices from different wakes. If vortices come in close proximity to each other, instability growth can be amplified leading to a more rapid decay of the vortices.

In this study we take a simple approach to estimate the effect of wake interaction on decay based on linear stability theory. It is assumed that the vortices continue to decay as described by the diffusion phase in Holzäpfel's model until either time $T_{2}^{*}$ is reached, or until a critical growth in amplitude of the vortex instabilities is reached. At that point it is assumed that the vortices follow the rapid decay rate used in Holzäpfel's model. The critical amplitude growth factor is estimated from linear stability theory for the wake behind a single wing at a given atmospheric condition. The wake is propagated out to time $T_{2}^{*}$, and the corresponding amplitude growth factor is taken to be the critical amplitude growth factor. An example is shown in Figure 8. In this case, vortex 2 and 3 reach the critical amplitude growth factor and start undergoing rapid decay. Vortex 1 has not yet reached time $T_{2}^{*}$ and is thus, still in the diffusion phase.

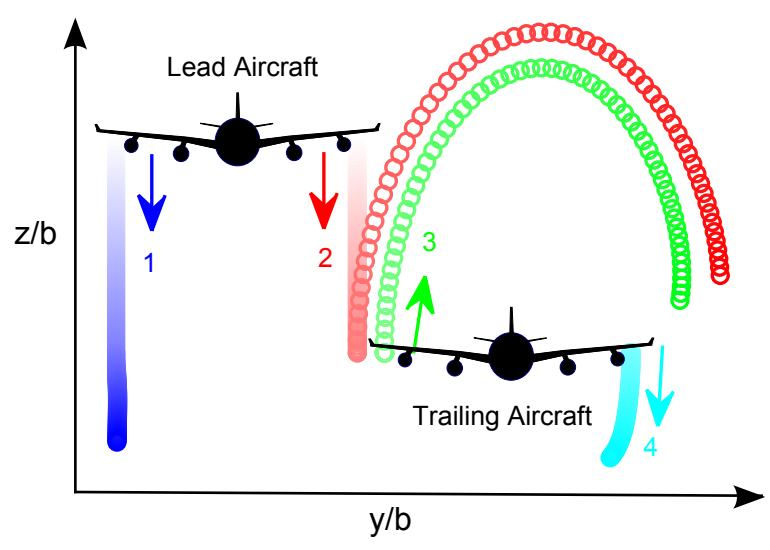

(a) Motion of vortices in y-z plane. Note proximity of vortex 2 and vortex 3 .

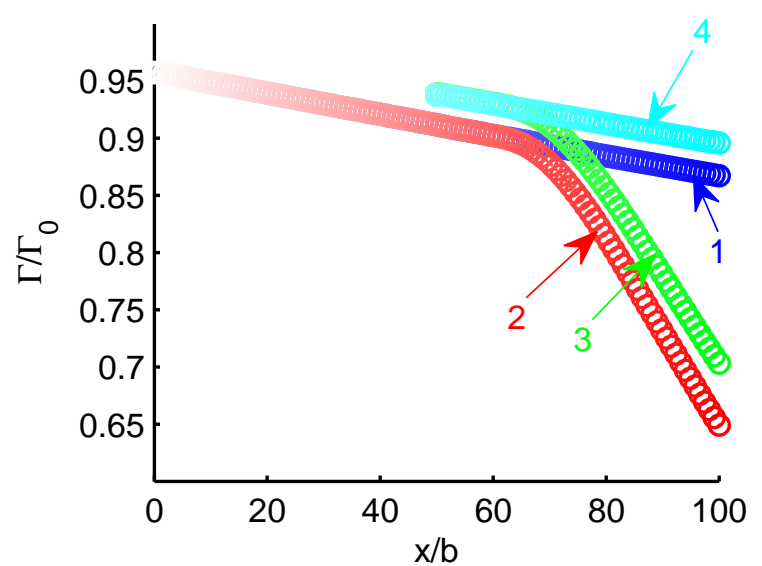

(b) Corresponding circulation decay as a function of streamwise distance.

Figure 8: An example showing vortices in close proximity entering rapid decay sooner due to growth in instabilities. $\left(\epsilon^{*}=0.2, N^{*}=0.7,50\right.$ span separation $)$

The linearized vortex filament method used follows the approach of Crouch. ${ }^{42}$ The location of vortex $\mathrm{n}$ is parameterized as

$$
\mathbf{r}_{\mathbf{n}}=x_{n} \mathbf{e}_{x}+\left(y_{n}(t)+\hat{y}_{n} e^{\mathbf{i} k x_{n}}\right) \mathbf{e}_{y}+\left(z_{n}(t)+\hat{z}_{n} e^{\mathbf{i} k x_{n}}\right) \mathbf{e}_{z}
$$

For a three aircraft formation, $n=4$ since there are two vortex pairs trailing from the lead and middle aircraft (Figure 9). Crouch linearized the above equation under the assumption that the perturbation amplitudes are small relative to the separation distance of the vortices. This assumption is not strictly true in cases where the vortices are close to one another. However, using a higher fidelity tool to predict perturbation growth would have been infeasible given the number of simulations performed, and the results presented here were found to be relatively insensitive to wake instability amplitude growth rate at the streamwise separation distances considered. With the disturbance vector proposed by Crouch, $\phi=\left(\hat{y}_{1}, \hat{y}_{2}, \hat{y}_{3}, \hat{y}_{4}, \hat{z}_{1}, \hat{z}_{2}, \hat{z}_{3}, \hat{z}_{4}\right)^{\top}$, linear stability theory leads to a set of equations $\frac{d \phi}{d t}=A \phi$.

The linear system of equations can then be solved to yield perturbation amplitudes for any time downstream. In the formation configurations studied here, it is the inner vortex pair that is of interest in tracking the instability amplitudes. Thus, we define $\phi_{i}=\left(\hat{y}_{2}, \hat{y}_{3}, \hat{z}_{2}, \hat{z}_{3}\right)^{\top}$ to be the inner vortex disturbance vector and the growth factor to be

$$
\text { growth factor }=\frac{\left\|\phi_{i}\right\|_{2}}{\left\|\phi_{i_{0}}\right\|_{2}}
$$




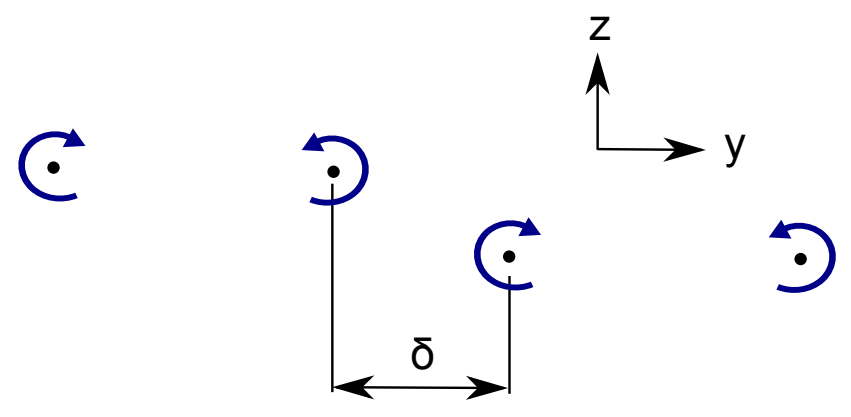

Figure 9: Depiction of a typical vortex configuration used in the linearized vortex filament method.

\section{E. Wake Propagation}

At each time step the decay of the vortices is updated and the induced velocities at all other vortices is computed. The effect of buoyancy due to stratification is incorporated using the method of Holzäpfel. ${ }^{38}$ This is essentially Greene's method ${ }^{33}$ with a slight modification to better match LES data. Buoyancy effects on wake propagation are typically negligible in this application unless the stratification is large, and streamwise separation between the aircraft is also large.

\section{F. Lift and Induced Drag}

Although not necessarily optimal, a typical lift distribution for a large commercial transport is used for the lead aircraft. For the trailing aircraft, the effect of the influence of the wake(s) from lead aircraft are used when computing the lift distribution. For each aircraft the angle of attack is adjusted so that each flies at the same lift coefficient, and ailerons are deflected anti-symmetrically to trim in roll. Ailerons are assumed to be along the outer $30 \%$ of the semi-span. Section lift coefficients are computed to ensure unrealistic deflections are not required to trim. The induced drag of the lead airplane is computed using a standard Trefftz plane method, since the trailing aircraft are far enough back that they are assumed to exert no influence on the lead aircraft. A near field method is used to compute the induced drag of each trailing aircraft due to its own normalwash and that from any wakes trailing upstream.

\section{G. Uncertainty Analysis}

Wake development is a stochastic process. There is variation in atmospheric conditions, stochastic behavior due to turbulence, and uncertainty in the parameters used in the models. Rather than use a deterministic model, many of the parameters in the model are assumed to be random variables sampled from a Gaussian distribution. For each random variable, reasonable bounds are established and assumed to be $\pm 3 \sigma$ events. The parameters assumed to be random variables, and their corresponding bounds are discussed in this section.

The rapid decay phase parameters $T_{2}^{*}$ and $\nu_{2}^{*}$, initial wake circulation, and vortex core size are all assumed to be random variables. Bounds on the wake decay parameters are the same as those used by Holzäpfel ${ }^{38}$ in his studies. Initial wake circulation after rollup is assumed to be known within $\pm 10 \%$. Variations in core size are estimated to be between $3 \%$ to $6 \%$ of the vortex size, as discussed previously.

Vortex instability growth depends on the wavenumber of the period disturbances, and the initial perturbations both of which are assumed to be random variables. The wavenumber of the periodic disturbances is assumed to vary between 0.6 to 1 . The initial perturbations in vortex position are not expected to follow a specific distribution, but are rather chosen randomly and then the initial perturbation vector is normalized to have norm 1.

Wind gradients and turbulent gusts add uncertainty in tracking the wake downstream. The stochastic nature of turbulence leads to variation in the wake's location. The estimation procedure for these bounds is similar to that done by Holzäpfel. ${ }^{41}$ It is assumed that the rms ambient turbulence velocity can be used to 
give reasonable bounds on the uncertainty in the wake position as follows

$$
y_{u, l}^{*}=y^{*} \pm \int q^{*} d t^{*}
$$

where $y_{u, l}^{*}$ represent the upper and lower bounds on normalized lateral position of the wake. If we assume that the turbulent eddy viscosity is constant between aircraft, and use an approximation relating turbulent eddy viscosity to rms turbulent velocity used by Donaldson ${ }^{25}$

$$
q=(8 \Lambda \epsilon)^{1 / 3}
$$

the bound on error in lateral position can be expressed after some rearranging as

$$
\frac{\Delta y}{b_{0}}= \pm \frac{1}{2 \pi} \frac{C_{L}}{A R_{0}}\left(\frac{\Lambda}{b_{0}}\right)^{1 / 3} \frac{\Delta x}{b_{0}} \epsilon^{*}
$$

The longitudinal length scale of the turbulence depends on stratification and altitude, but since it appears in the equation as $\Lambda^{1 / 3}$ it need only be known within the right order of magnitude. Greene estimates that this parameter should be between $b_{0}$ to $8 b_{0}$ for many different aircraft and atmospheric conditions. ${ }^{33}$ Thus, $\Lambda$ is included as a random variable with those bounds. As seen in the equation, the uncertainty in wake location depends mainly on atmospheric turbulence and how far apart the aircraft are spaced downstream. The equation for vertical uncertainty in wake location is of the same form.

Even with precise knowledge and predictive ability of wake location, there will still be tracking error due to control limitations. The tracking error used in this analysis is based on close formation flight tests conducted by NASA using two F/A-18 airplanes. ${ }^{43}$ In the tests, steady state tracking accuracy was always better than $\pm 9 \mathrm{ft}$ in zero to low turbulence conditions. Although, as compared to close formation flight, the location of the wake is more uncertain for extended formations, this analysis assumes that similar tracking accuracy will be achievable. Successful implementation will likely require the use of technologies other than differential GPS to track the location of the wake (such as LIDAR or exhaust gas temperature monitoring). In any case, the results presented here assume that the aircraft is able to position itself optimally with respect to the wake to within $\pm 9 \mathrm{ft}$.

Finally, there is uncertainty in atmospheric properties. These, however are not assumed to follow a known distribution. Because atmospheric properties depend strongly on many variables such as location, season, altitude, time of day, etc. a "typical distribution" may be misleading. Instead, specific values are used in order to show the effect of different levels of atmospheric turbulence and stratification. The atmosphere is often unstably stratified at altitude, but can be strongly stratified at times. A value of $N^{*}=1$ is a rough upper limit corresponding to aircraft with large spans and an atmosphere with a high lapse rate. Values for the normalized eddy dissipation rate can be roughly divided into three regions. Values below 0.02 correspond to weak atmospheric turbulence, between 0.02-0.2 to moderate turbulence, and anything larger than 0.3 as strong atmospheric turbulence. ${ }^{34}$ Strong atmospheric turbulence levels are of less interest in this study, since extended formation flight would not be used in such atmospheric conditions.

For each given formation and atmospheric condition, the optimal positioning of the aircraft is first found assuming no uncertainty in the parameters. This optimal spacing is used as a starting point for the Monte Carlo simulations. Optimization is performed using the sequential quadratic programming method, with gradients computed by finite differencing. This does not imply that the expected value of the Monte Carlo simulations should approach the optimal solution, in fact it is far from that. It merely provides a reasonable starting point assuming one might try to position the aircraft optimally if there was no variation in the parameters. Three hundred Latin Hypercube samples are used for each simulation to characterize the uncertainty in the formation's performance. While there are more efficient methods to characterize uncertainty, the analysis is fast enough that these tools are sufficient. A summary of the various uncertainty bounds used in this analysis is provided in Table 1. 
Table 1: Variation of parameters assumed to be random variables sampled from a Gaussian distribution

\begin{tabular}{ccc}
\hline \hline & $-3 \sigma$ & $+3 \sigma$ \\
\hline Time when rapid decay phase begins & function of turbulence, and stratification (weakly) \\
Rapid decay rate & function of stratification \\
Initial circulation after wake rollup & $90 \% \Gamma_{0}$ & $110 \% \Gamma_{0}$ \\
Vortex core size relative to vortex size & $3 \%$ & $6 \%$ \\
Wavenumber of period disturbance & 0.6 & 1 \\
Initial perturbation in vortex positions $(4)$ & random numbers s.t. $\left\|\phi_{i_{0}}\right\|_{2}=1$ \\
Longitudinal integral scale of turbulence & $1 b_{0}$ & $8 b_{0}$ \\
Vortex position (2) & function of turbulence, and aircraft streamwise spacing \\
Tracking error (4) & $-9 \mathrm{ft}$ & $+9 \mathrm{ft}$ \\
\hline \hline
\end{tabular}

\section{Formation Comparisons}

In addition to a two aircraft formation, three different types of three aircraft formations are explored in this analysis (Figure 10). The $\mathrm{V}$ formation is similar to a typical $\mathrm{V}$ formation, but the trailing aircraft is further back in the streamwise direction to maintain separation between the different aircraft. The same is true of the inverted- $\mathrm{V}$ formation. The figure is only representative, as the streamwise separation distances are actually much larger for extended formation flight.

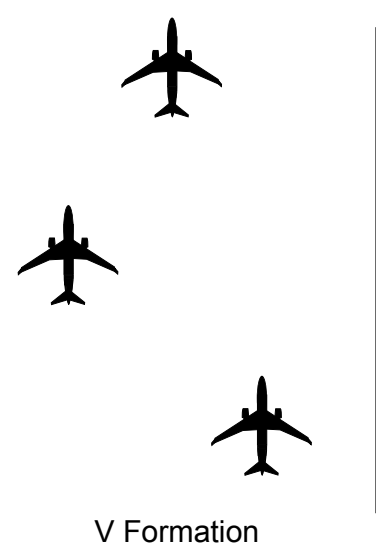

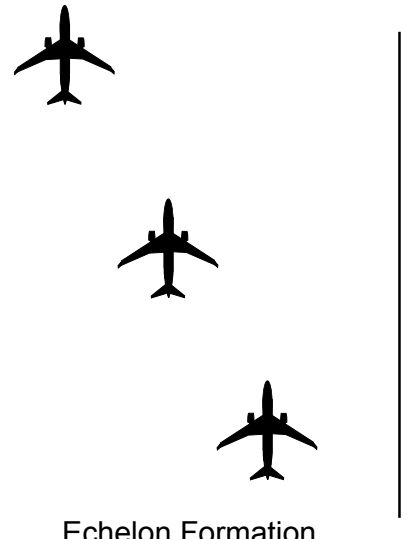

Echelon Formation
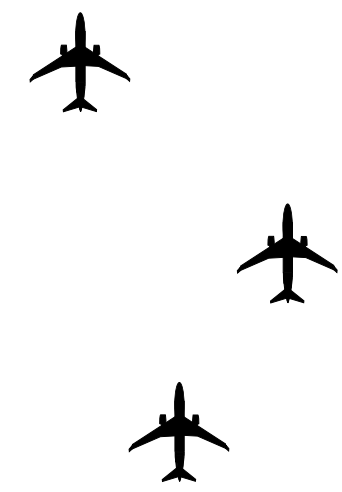

Inverted-V Formation

Figure 10: Three-aircraft formation types explored in the analysis.

First, the effect of turbulence on induced drag savings is examined. The streamwise spacing between aircraft is fixed at 20 spans. At these separation distances the effect of stratification is negligible since stratification mainly affects the rapid decay rate of the vortices. Figure 11 shows the induced drag of the formations as a function of normalized eddy dissipation rate. Labeled on the $\mathrm{x}$-axis are the regions which roughly correspond to low and high levels of turbulence. The eddy dissipation rate is plotted on a log scale to more easily see the rise in drag with turbulence. At normalized eddy dissipation rates below about 0.05 , the induced drag is essentially unaffected by turbulence level. At higher turbulence levels the formation induced drag fraction increases linearly with $\epsilon^{*}$ (exponential increase on a log-plot). Three aircraft formations provide about $13 \%$ additional formation induced drag savings on average as compared to two aircraft formations at these separation distances in low to moderate-low turbulence. Subsequent cases shown in this paper use fixed $\epsilon^{*}$ values of 0.02 and 0.2 , which correspond to the low and high end of moderate turbulence values. The latter value is not used to suggest that extended formation flight is practical at those higher turbulence levels, but is intended to demonstrate the effect of turbulence on performance.

The turbulence and stratification level is now fixed and streamwise separation between the aircraft is varied instead. Four combinations of turbulence and stratification levels are analyzed. The mean performance 


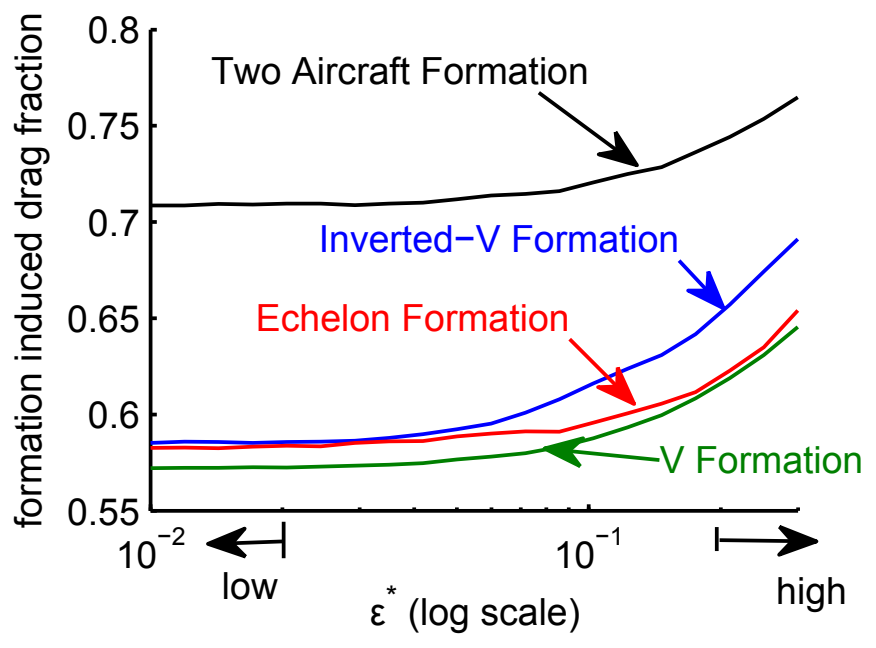

Figure 11: Mean formation induced drag fraction as a function of turbulence level with 20 spans streamwise spacing.

from Monte Carlo simulations is shown in Figure 12. As seen, the level of turbulence can play a significant role in performance. This is particularly pronounced at larger streamwise separation distances because of the effect of gusts on the vortex position. Stratification has more of an effect on the three aircraft formations because the separation distance from the lead aircraft to the trailing aircraft is twice as long as the corresponding two aircraft formations. However, as seen from the figures the effect is still relatively minor.

Of the three aircraft formations, the inverted- $\mathrm{V}$ formation seems to consistently perform a few percent worse than the others. The reason for this is that almost all the drag savings are realized only by the trailing aircraft, whereas in the other two three-aircraft-formations the drag savings are more evenly distributed between the second and third aircraft. In a stochastic environment this makes the inverted- $\mathrm{V}$ formation more sensitive to variation. However, unlike the other formations, the inverted-V formation has a nearly symmetric lift distribution on the trailing aircraft. This has some unmodeled advantages which should be kept in mind while interpreting these results. One of these is trim drag due to roll. In this analysis, each configuration is trimmed in roll and any inviscid trim drag penalties are captured. However, if viscous drag were included in the analysis, the two aircraft, $\mathrm{V}$, and echelon formations would have a more significant viscous trim drag penalty since they carry a more unbalanced load distribution. Even more important are transonic considerations. The larger aileron deflections required for the two aircraft, $\mathrm{V}$, and echelon formations can be problematic at transonic speeds due to increased drag, buffet, etc. In addition, structural and control considerations would likely favor the more symmetric loading of the inverted- $\mathrm{V}$ formation.

The echelon formation is seen to deviate from the performance of the other three aircraft formations at large separation distances. This is shown more explicitly in Figure 13 which shows the corresponding $90 \%$ confidence intervals for the $\epsilon=0.02$ cases. The $\epsilon=0.2$ cases are not shown here because the three aircraft formations are all very similar, and a different comparison is shown later. The large variation in the echelon's performance can be explained by the path of the vortex propagation. In a $\mathrm{V}$ or echelon formation two of the vortices are in close proximity. This causes that pair of vortices to both propagate and decay at an accelerated rate. Because the strength of the vortex from the second aircraft is stronger than that of the lead aircraft (especially at larger separation distances) that vortex pair tends to move away from the lead aircraft's wake (see Figure 14). In a $\mathrm{V}$ formation this means that this pair of vortices moves away from the trailing aircraft, but in a echelon formation the trailing aircraft may be flying near the path of these vortices. Depending on the the position of the aircraft and the vortex, this can either increase or decrease the induced drag savings experienced by the trailing aircraft. Because this relative positioning is sensitive to many factors, the echelon formation exhibits a larger uncertainty in drag reduction. Regardless of whether or not this phenomena is used to increase or decrease drag, if the trailing aircraft flies through the interacting vortices it can have a negative impact on ride quality. This is due to the acceleration of the growth rate of the perturbation amplitudes of the pair of vortices in close proximity. Thus, although 


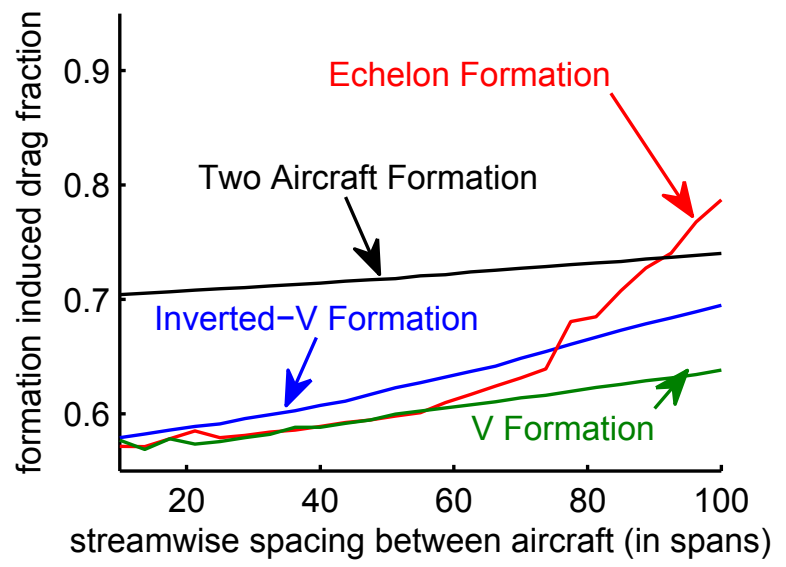

(a) $\epsilon^{*}=0.02, N^{*}=0$

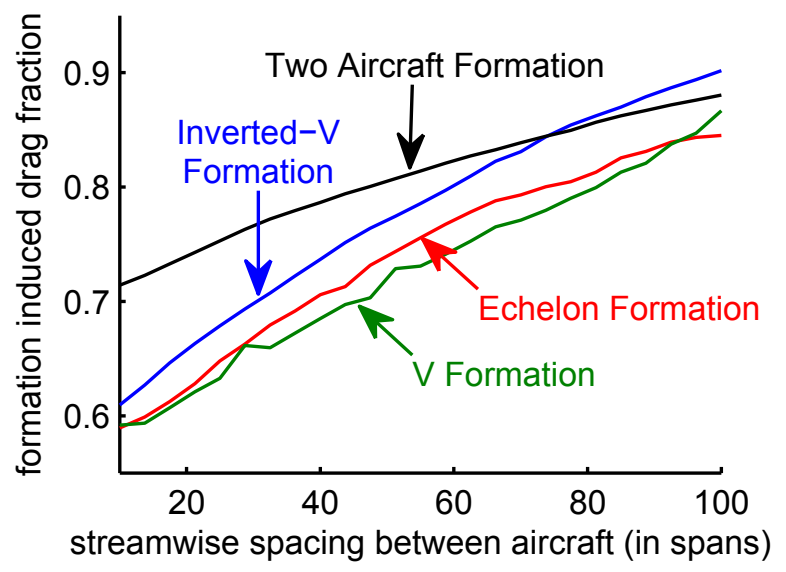

(c) $\epsilon^{*}=0.2, N^{*}=0$

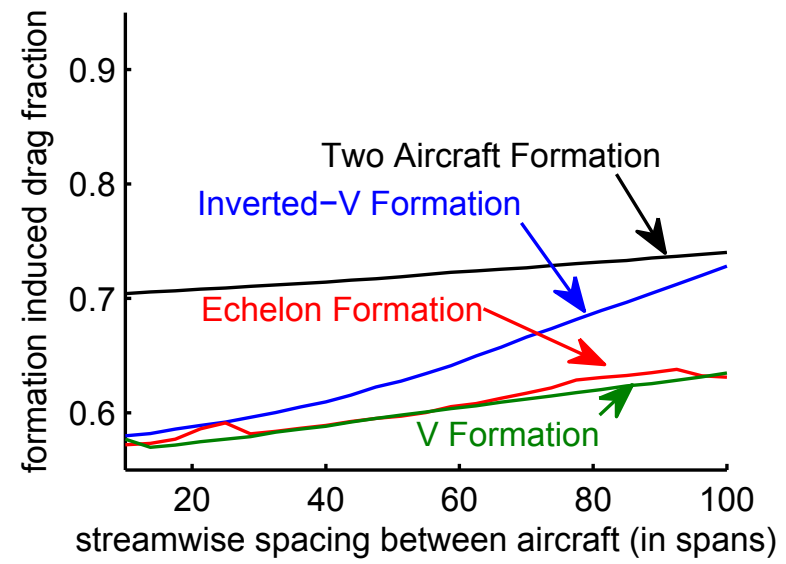

(b) $\epsilon^{*}=0.02, N^{*}=0.7$

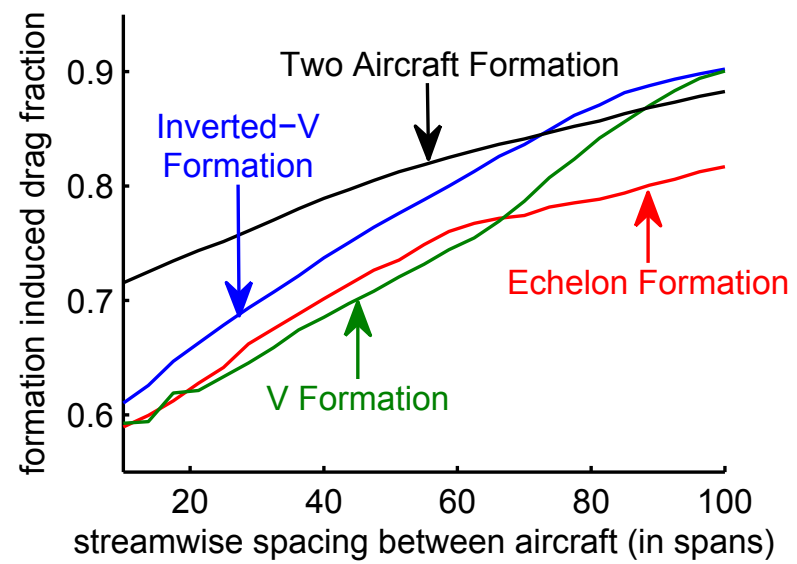

(d) $\epsilon^{*}=0.2, N^{*}=0.7$

Figure 12: Mean formation induced drag fraction as a function of streamwise separation distance. 


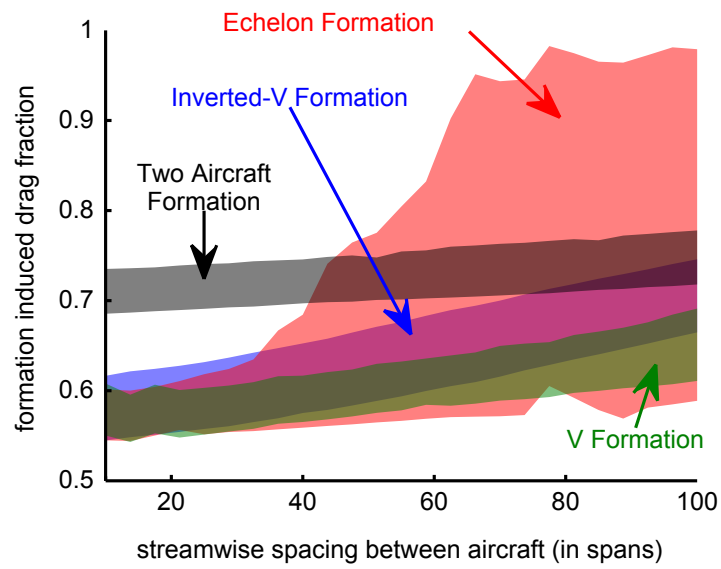

(a) $N^{*}=0$

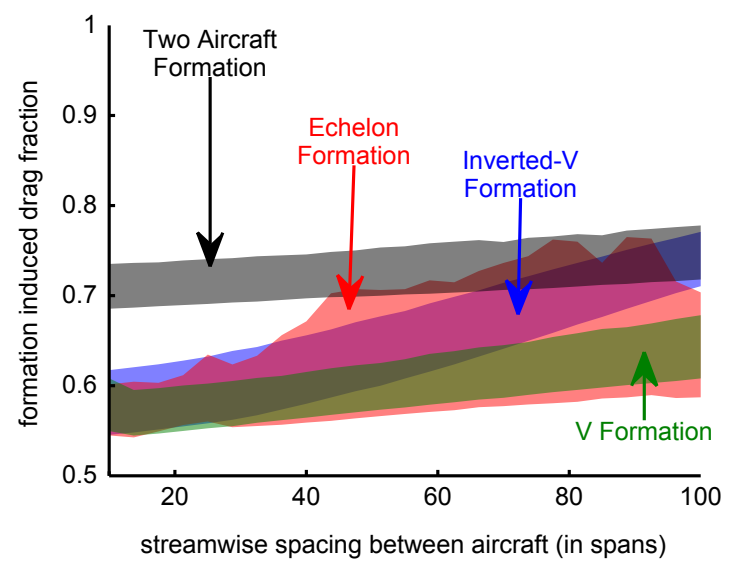

(b) $N^{*}=0.7$

Figure 13: $90 \%$ confidence intervals of formation induced drag fraction $\left(\epsilon^{*}=0.02\right)$.

optimization methods could find "optimal" formations that exploit this phenomena, this may come with an unacceptable degradation in ride quality.

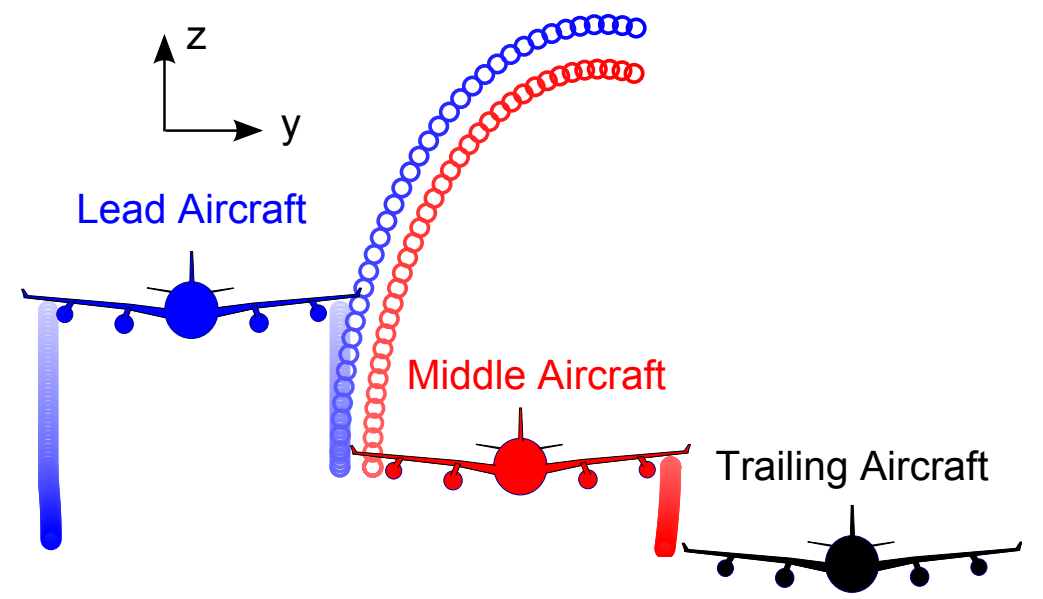

Figure 14: Wake propagation history starting at lead aircraft and ending at trailing aircraft for a typical echelon (or V) formation.

Figure 15 shows $90 \%$ confidence intervals of the aggregate of the previous data separated by turbulence level. The results from the echelon formation at large separation distances are excluded from the results, because of the ride quality issues discussed previously. For separation distances less than about 20 spans all of the three aircraft formations achieve essentially the same performance. In the low-moderate turbulence case with 20 spans streamwise separation, a two aircraft formation saves between $26-31 \%$ in induced drag, while a three aircraft formations saves between $38-45 \%$ in induced drag (90\% confidence intervals). These lower turbulent levels are more representative of conditions that formation flight would be employed in. 


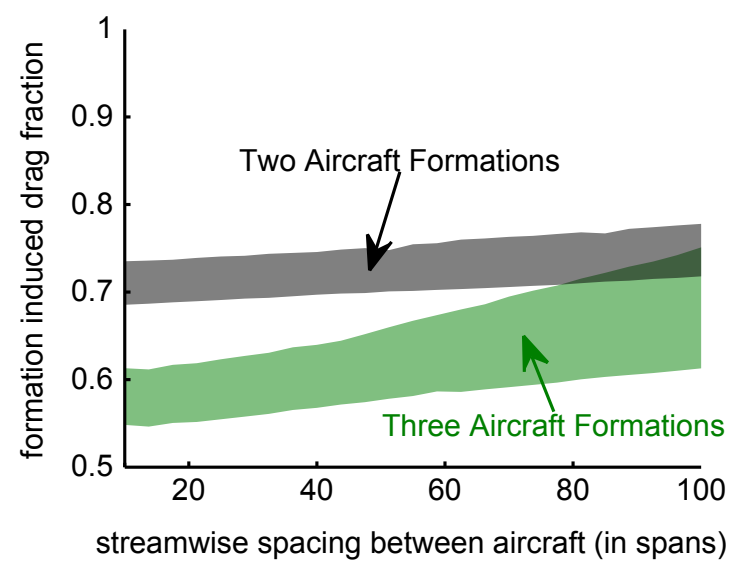

(a) Low-moderate turbulence $\left(\epsilon^{*}=0.02\right)$

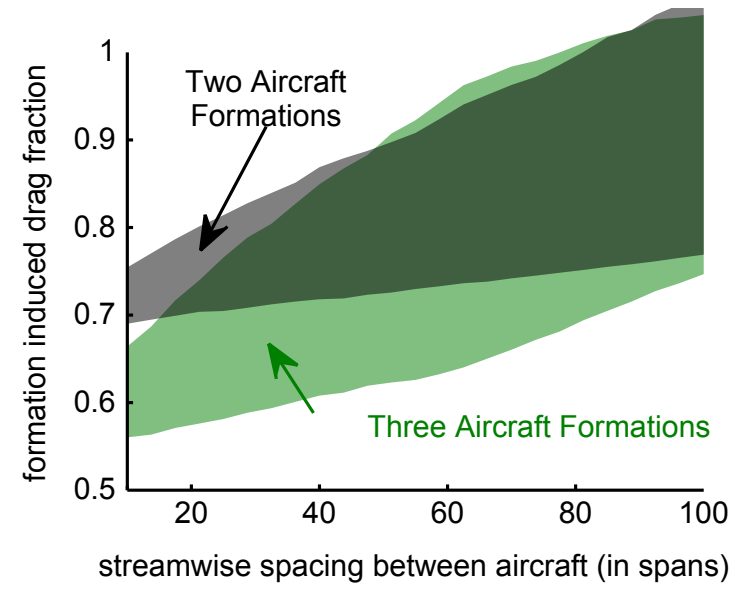

(b) Moderate-high turbulence $\left(\epsilon^{*}=0.2\right)$

Figure 15: Comparison between two and three aircraft formations. 90\% confidence interval for all stratification levels and formation configurations previously examined.

\section{Contributions to Variance in Drag Savings}

To understand which factors contribute the most to the variation in performance, Monte Carlo simulations are re-run varying one parameter at a time while holding all the others fixed at their mean values. Of course different combinations of parameters can have important effects, but this should give us a good idea of what the dominant sources of uncertainty are. Results for the two aircraft formation are shown first. The breakdown of the relative contribution of each parameter to the total variance $\left(\sigma^{2}\right)$ is shown for $\epsilon^{*}=0.02$ and $\epsilon^{*}=0.2$ in Figures $16 \mathrm{a}$ and $16 \mathrm{~b}$ respectively. Other parameters not labeled are negligible, or do not contribute to the variation in a two aircraft formation because of the smaller separation distances (rapid decay and vortex instability parameters).

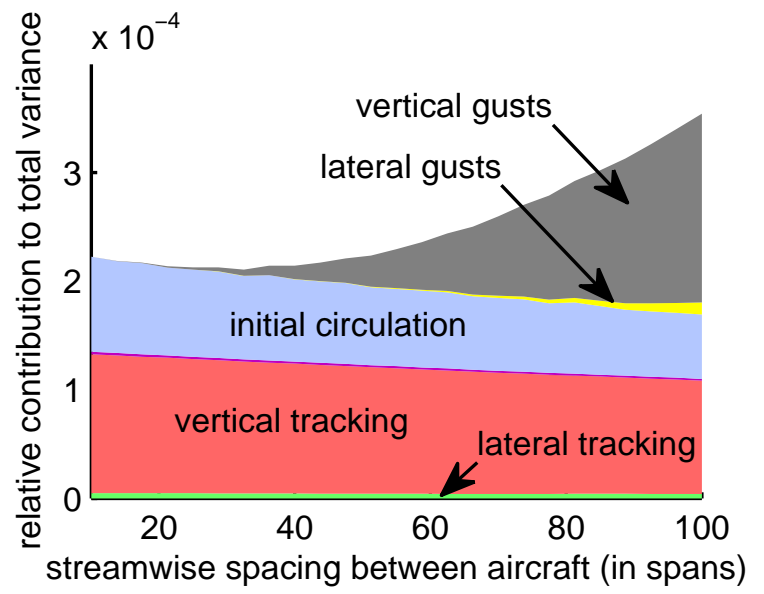

(a) $\epsilon^{*}=0.02$

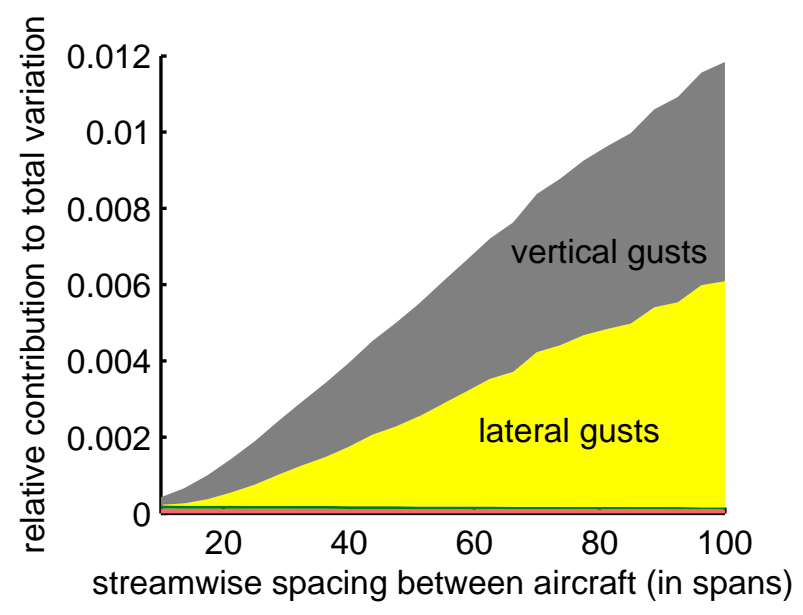

(b) $\epsilon^{*}=0.2$

Figure 16: The relative contributions of total variation $\left(\sigma^{2}\right)$ in formation induced drag for a two aircraft formation.

Tracking error is the dominant source of error for low to moderate-low levels of turbulence and streamwise spacings less than about 75 spans. The trailing wakes are assumed to be rigid, and tracking error here only refers to the positioning limitations of the control system based on data from the NASA flight tests, as discussed previously. Variation due to inital circulation after rollup is also seen to be significant. However, 
the variation in circulation used is rather large for this low turbulence scenario. In any case, variance in initial circulation would on average have no effect on the formation induced drag since perturbations can either increase or decrease the drag savings and do so relatively symmetrically. In contrast, variation in tracking position in any direction results in increased drag (assuming that the aircraft would be positioned optimally if no error existed). For higher turbulence levels, the variation due to turbulent gusts is dominant. Advances in technology can be used to help decrease the dominant contributions to the variance. Precision navigation techniques and remote sensing technology such as LIDAR can help decrease relative positioning error. Still, formation flight is more practical where turbulent gusts do not play a significant role. This corresponds to low to moderate-low turbulence with streamwise separation distances less than about 75 spans for a two aircraft formation.

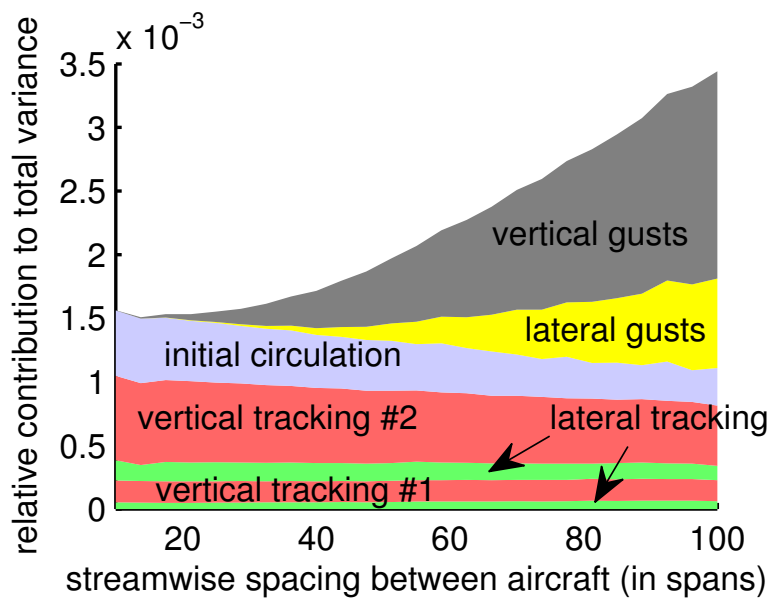

(a) $\epsilon^{*}=0.02$

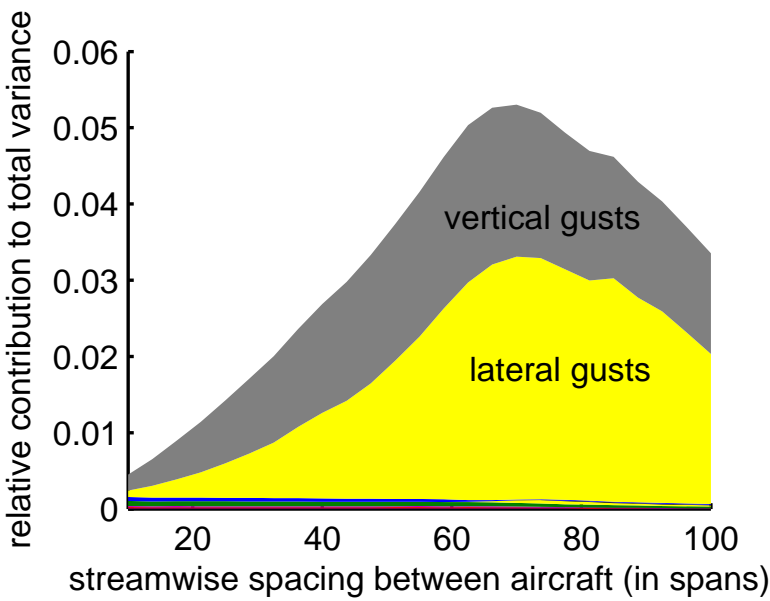

(b) $\epsilon^{*}=0.2$

Figure 17: The relative contributions of total variation in formation induced drag for an inverted-V formation.

The contributions to total variance is also shown for an inverted- $\mathrm{V}$ three aircraft formation. Turbulence levels of $\epsilon^{*}=0.02$ and $\epsilon^{*}=0.2$ are shown in Figures 17a and $17 \mathrm{~b}$ respectively. The labels \#2 and \#3 refers to the tracking error for the second and third aircraft of the formation respectively. The total variance is of course larger for these cases compared to the two aircraft formation, but the relative contributions to the variance are fairly similar. Gusts, however, start to contribute more variance at smaller streamwise separations. Thus, three aircraft formations are likely only practical in low to moderate-low turbulent settings with streamwise separation distances less than about 50 spans. For the moderate-high turbulence case we see that the total variance begins to taper off after about 75 spans. The reason for this is that the rapid decay phase begins around that distance, and thus the upstream wakes start to have less of an effect on the trailing aircraft.

\section{Conclusion}

Extended formation flight shows promise for offering significant reductions in induced drag in a realistic environment. By extended formation flight we mean formations with aircraft separated by more than ten spans in the streamwise direction for safety reasons. A Betz wake model based on far field conservation principles, is modified with an empirically based core size. This simple method is found to agree well with more sophisticated calculations (2D N-S) for the upwash distributions from a rolled up wake. Two phase wake decay models developed extensively by Holzäpfel ${ }^{36,38,41}$ are used to propogate the wake downstream. Monte Carlo simulations are incorporated to allow for realistic variation and uncertainty in parameters affecting wake decay, wake instabilities, wake propagation, and aircraft tracking. The main conclusions of the analysis are:

- For streamwise separation distances less than about 30 spans in low to moderately low turbulence levels, a two aircraft formation achieves a maximum reduction in induced drag of $30 \pm 3 \%$, while a three aircraft formation achieves a maximum reduction of $40 \pm 6 \%$ (95\% confidence intervals). At 
these distances, the different configurations of three aircraft formations achieve essentially the same aerodynamic performance.

- An inverted-V formation is more sensitive to variation in induced drag savings, but may be more advantageous due to its more symmetric loading on the trailing aircraft.

- Tracking error is the largest source of variation in induced drag savings. Technology in precision navigation and remote sensing may be useful to help minimize this variation.

- Extended formation flight may only be practical for low to moderately low turbulence levels with streamwise spacings less than about 40 spans. At larger separation distances turbulent gusts start to play a dominant role in the variation in performance.

Extended formation flight is a concept with the potential to significantly improve the efficiency of longrange flights. However, as mentioned, there are a number of considerations that still need to be evaluated before formation flight can be considered practical in a commercial environment. For aircraft that fly at transonic speeds, the change in loading (both from the upstream wake and from the deflection of control surfaces in order to trim) can give rise to significant compressibility drag penalties. High-fidelity simulations are needed to determine the magnitude of the compressibility effects, and how best to address them. Other considerations are difficult to assess by simulation alone, such as the effect on the handling and ride quality due to flying through the wake of another aircraft. There are many open questions regarding the guidance, navigation, and control strategies of formation flight, ranging from the type of sensors to be used, to the amount of energy expended by the control system to maintain formation. Some additional considerations include the impact and strategies for formations of dissimilar aircraft, formations composed of a larger number of aircraft, and routing of formations. We are currently exploring some of these areas in order to more fully evaluate the potential of using formation flight for the purpose of reducing fuel consumption.

\section{Acknowledgments}

The authors gratefully acknowledge support from the National Defense Science and Engineering Graduate (NDSEG) Fellowship program, and the National Science Foundation (NSF) Graduate Research Fellowships Program. We would also like to thank Airbus and the Fly Your Ideas Challenge for their feedback and encouragement related to some of the concepts discussed here.

\section{References}

\footnotetext{
${ }^{1}$ Wieselsberger, C., "Beitrag zur erklarung des winkelfluges eineger zugvogel," Z. Flugtechnik E Motorluftschiffahrt, Vol. 5, 1914, pp. 225-229.

${ }^{2}$ Lissaman, P. and Shollenberger, C., "Formation Flight of Birds," Science, Vol. 168, 1970, pp. 1003-1005, doi:10.1126/science.168.3934.1003.

${ }^{3}$ Hummel, D., "Aerodynamic Aspects of Formation Flight in Birds," Journal of Theoretical Biology, Vol. 104, No. 3, 1983, pp. 321-347, doi:10.1016/0022-5193(83)90110-8.

${ }^{4}$ Hummel, D., "Formation Flight as an Energy-Saving Mechanism," Journal of Zoology, Vol. 41, No. 3, 1995, pp. 261-278.

${ }^{5}$ Weimerskirch, H., Martin, J., Clerquin, Y., Alexandre, P., and Jiraskova, S., "Energy Saving in Flight Formation," Nature, Vol. 413, No. 6857, 2001, pp. 697-698.

${ }^{6}$ Hummel, D., "The Use of Aircraft Wakes to Achieve Power Reductions," AGARD CP-584, May 1996.

${ }^{7}$ Blake, W. and Multhopp, D., "Design, Performance and Modeling Considerations for Close Formation Flight," AIAA Atmospheric Flight Mechanics Conference and Exhibit, AIAA-1998-4343, August 1998.

${ }^{8}$ Wagner, G., Jacques, D., Blake, B., and Pachter, M., "An Analytical Study of Drag Reduction in Tight Formation Flight," AIAA Atmospheric Flight Mechanics Conference and Exhibit, AIAA-2001-4075, August 2001.

${ }^{9}$ Blake, W. and Gingras, D., "Comparison of Predicted and Measured Formation Flight Interference Effects," Journal of Aircraft, Vol. 41, No. 2, 2004, pp. 201-207.

${ }^{10}$ Wagner, G., Jacques, D., Blake, W., and Pachter, M., "Flight Test Results of Close Formation Flight for Fuel Savings," AIAA Atmospheric Flight Mechanics Conference and Exhibit, AIAA-2002-4490, August 2002.

${ }^{11}$ Cobleigh, B., "Capabilities and Future Applications of the NASA Autonomous Formation Flight (AFF) Aircraft," 1st UAV Conference, AIAA-2002-3443, May 2002.

${ }^{12}$ Ray, R., Cobleigh, B., Vachon, M., and John, C. S., "Flight Test Techniques Used to Evaluate Performance Benefits During Formation Flight," AIAA Atmospheric Flight Mechanics Conference and Exhibit, AIAA-2002-4492, August 2002.

${ }^{13}$ Vachon, M., Ray, R., Walsh, K., and Ennix, K., "F/A-18 Aircraft Performance Benefits Measured During the Autonomous Formation Flight Project," AIAA Atmospheric Flight Mechanics Conference and Exhibit, AIAA-2002-4491, August 2002.
} 
${ }^{14}$ Bower, G., Flanzer, T., and Kroo, I., "Formation Geometries and Route Optimization for Commercial Formation Flight," AIAA Applied Aerodynamics Conference, AIAA-2009-3615, June 2009.

${ }^{15}$ Munk, M., "The Minimum Induced Drag Of Aerofoils," NACA TR-121, 1979.

${ }^{16}$ Widnall, S., "The Structure and Dynamics of Vortex Filaments," Annual Review of Fluid Mechanics, Vol. 7, No. 1, 1975, pp. 141-165, doi:10.1146/annurev.fl.07.010175.001041.

${ }^{17}$ Gerz, T. and Holzaepfel, F., "Wing-tip Vortices, Turbulence, and the Distribution of Emissions," AIAA Journal, Vol. 37, No. 10, 1999, pp. 1270-1276, doi:10.2514/2.595.

${ }^{18}$ Durand (editor), W., Aerodynamic Theory, Vol. E of II, Durand Reprinting Committee, 1943, pp. 328-330.

${ }^{19}$ Milne-Thomson, L., Theoretical Aerodynamics, Courier Dover Publications, 1973.

${ }^{20}$ Spreiter, J. and Sacks, A., "The Rolling Up of the Trailing Vortex Sheet and Its Effect on the Downwash Behind Wings," Jour. Aero. Sci, Vol. 18, No. 1, 1951, pp. 21-32.

${ }^{21}$ Spalart, P., "Airplane Trailing Vortices," Annual Review of Fluid Mechanics, Vol. 30, No. 1, 1998, pp. 107-138, doi:10.1146/annurev.fluid.30.1.107.

${ }^{22}$ Betz, A., "Behavior of Vortex Systems," NACA TM-713, 1933.

${ }^{23}$ Donaldson, C., "A Brief Review of the Aircraft Trailing Vortex Problem," AFOSR-TR-71-1910, Aeronautical Research Associates of Princeton, May 1971.

${ }^{24}$ Donaldson, C., Snedeker, R., and Sullivan, R., "Calculation of Aircraft Wake Velocity Profiles and Comparison with Experimental Measurements," Journal of Aircraft, Vol. 11, No. 9, 1974, pp. 547-555, doi:10.2514/3.60385.

${ }^{25}$ Donaldson, C., Bilanin, A., and Korkegi, R., "Vortex Wakes of Conventional Aircraft," AGARD-AG-204, Advisory Group for Aerospace Research and Development, May 1975.

${ }^{26}$ Rossow, V., "On the Inviscid Rolled-Up Structure of Lift-Generated Vortices," Journal of Aircraft, Vol. 10, No. 11, 1973, pp. 647-650, doi:10.2514/3.60277.

${ }^{27}$ Jordan, P., "Structure of Betz Vortex Cores," Journal of Aircraft, Vol. 10, 1973, pp. 691-693, doi:10.2514/3.60285.

${ }^{28}$ Rossow, V., "Application of Vortex Invariants to Roll Up of Vortex Pairs," Journal of Aircraft, Vol. 41, No. 5, 2004, pp. 1098-1105, doi:10.2514/1.1491.

${ }^{29}$ Mason, W., Farfield Structure of an Aircraft Trailing Vortex, Including Effects of Mass Injection, Master's thesis, Virginia Polytechnic Institute and State University, Blacksburg, VA, November 1971.

${ }^{30}$ Delisi, D., Greene, G., Robins, R., Vicroy, D., and Wang, F., "Aircraft Wake Vortex Core Size Measurements," AIAA Applied Aerodynamics Conference, AIAA-2003-3811, June 2003.

${ }^{31}$ McCormick, B., Tangler, J., and Sherrier, H., "Structure of Trailing Vortices," Journal of Aircraft, Vol. 5, No. 3, 1968, pp. 260-267, doi:10.2514/3.43936.

${ }^{32}$ Spalart, P. and Wray, A., "Initiation of the Crow Instability by Atmospheric Turbulence," The Characterisation and Modification of Wakes from Lifting Vehicles in Fluids, November 1996.

${ }^{33}$ Greene, G., "An Approximate Model of Vortex Decay in the Atmosphere," Journal of Aircraft, Vol. 23, No. 7, 1986, pp. 566-573, doi:10.2514/3.45345.

${ }^{34}$ Sarpkaya, T., "New Model for Vortex Decay in the Atmosphere," Journal of Aircraft, Vol. 37, No. 1, 2000, pp. 53-61, doi:10.2514/2.2561.

${ }^{35}$ Crow, S. and Bate, E., "Lifespan of Trailing Vortices in a Turbulent Atmosphere," Journal of Aircraft, Vol. 13, 1976, pp. 476-482, doi:10.2514/3.44537.

${ }^{36}$ Holzäpfel, F., "Probabilistic Two-Phase Aircraft Wake-Vortex Model: Further Development and Assessment," Journal of Aircraft, Vol. 43, No. 3, 2006, pp. 700-708, doi:10.2514/1.16798.

${ }^{37}$ Holzäpfel, F., Gerz, T., and Baumann, R., "The Turbulent Decay of Trailing Vortex Pairs in Stably Stratified Environments," Aerospace Science and Technology, Vol. 5, No. 2, 2001, pp. 95-108, doi:10.1016/S1270-9638(00)01090-7.

${ }^{38}$ Holzäpfel, F., "Probabilistic Two-Phase Wake Vortex Decay and Transport Model," Journal of Aircraft, Vol. 40, No. 2, 2003, pp. 323-331, doi:10.2514/2.3096.

${ }^{39}$ Jackson, W., Yaras, M., Harvey, J., Winckelmans, G., Fournier, G., and Belotserkovsky, A., "Wake Vortex Prediction-An Overview," TP 13629E, Transportation Development Centre, March 2001.

${ }^{40}$ Ciffone, D. and Orloff, K., "Far-Field Wake-Vortex Characteristics of Wings," Journal of Aircraft, Vol. 12, No. 5, 1975, pp. 464-470, doi:10.2514/3.59825.

${ }^{41}$ Holzäpfel, F. and Robins, R., "Probabilistic Two-Phase Aircraft Wake-Vortex Model: Application and Assessment," Journal of Aircraft, Vol. 41, No. 5, 2004, pp. 1117-1126, doi:10.2514/1.2280.

${ }^{42}$ Crouch, J., "Instability and Transient Growth for Two Trailing-Vortex Pairs," Journal of Fluid Mechanics, Vol. 350, 1997, pp. 311-330, doi:10.1017/S0022112097007040.

${ }^{43}$ Hanson, C., Ryan, J., Allen, M., and Jacobson, S., "An Overview of Flight Test Results for a Formation Flight Autopilot," NASA/TM-2002-210729, 2002. 